\title{
The impact of DIDS-induced inhibition of voltage-dependent anion channels (VDAC) on cellular response of lymphoblastoid cells to ionizing radiation.
}

\author{
Magdalena Skonieczna, Artur Cieslar-Pobuda, Yuriy Saenko, Marek Foksinski, Ryszard \\ Olinski, Joanna Rzeszowska-Wolny and Emilia Wiechec
}

\section{Journal Article}

\section{Tweet}

N.B.: When citing this work, cite the original article.

Original Publication:

Magdalena Skonieczna, Artur Cieslar-Pobuda, Yuriy Saenko, Marek Foksinski, Ryszard Olinski, Joanna Rzeszowska-Wolny and Emilia Wiechec, The impact of DIDS-induced inhibition of voltage-dependent anion channels (VDAC) on cellular response of lymphoblastoid cells to ionizing radiation., Medicinal chemistry, 2017. 13(8) http://dx.doi.org/10.2174/1573406413666170421102353

Copyright: Bentham Science Publishers http://www.benthamscience.com/

Postprint available at: Linköping University Electronic Press

http://urn.kb.se/resolve?urn=urn:nbn:se:liu:diva-137275

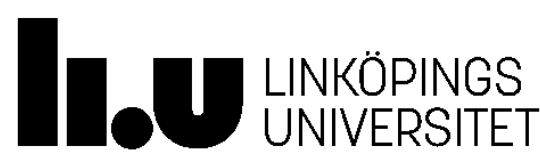




\section{The impact of DIDS-induced inhibition of voltage-dependent anion channels (VDAC) on cellular response of lymphoblastoid cells to ionizing radiation.}

Running title: DIDS radiosensitizes cancer cells

Magdalena Skonieczna ${ }^{\mathrm{a}, b^{*}}$, Artur Cieślar-Pobuda ${ }^{\mathrm{a}, c^{*}}$, Yuriy Saenko ${ }^{\mathrm{d}}$, Marek Foksiński ${ }^{\mathrm{e}}$, Ryszard Oliński ${ }^{\mathrm{e}}$, Joanna Rzeszowska-Wolny ${ }^{\mathrm{a}, \mathrm{b} \dagger}$, Emilia Wiechec ${ }^{\mathrm{f \dagger} @}$

${ }^{\mathrm{a}}$ Institute of Automatic Control, Silesian University of Technology, Akademicka 16, 44-100, Gliwice, Poland.

${ }^{\mathrm{b}}$ Biotechnology Centre, Silesian University of Technology, Krzywoustego 8, 44-100, Gliwice, Poland.

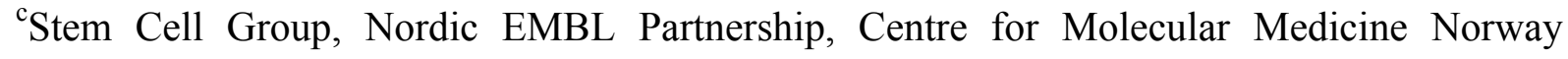
(NCMM), University of Oslo, P.O. Box 1137, Blindern 0318 Oslo, Norway

${ }^{\mathrm{d}}$ Laboratory of Molecular and Cell Biology, S.P.Kapitsa Technological Research Institute, Ulyanovsk State University, Lva Tolstogo 42, 432970 Ulyanovsk, Russian Federation.

${ }^{\mathrm{e}}$ Department of Clinical Biochemistry, Faculty of Pharmacy, Collegium Medicum in Bydgoszcz, Nicolaus Copernicus University in Torun, Karłowicza 24, Bydgoszcz 85-092, Poland

${ }^{\mathrm{f}}$ Department of Clinical and Experimental Medicine (IKE), Division of Cell Biology, Linköping University, 58185 Linköping, Sweden

* Authors share equal contribution; $\uparrow$ Authors share senior authorship

(a) Corresponding author: Emilia Wiechec, $\mathrm{PhD}$

Department of Clinical and Experimental Medicine (IKE)

Linköping University; Pathology Building, Level 9; 58185 Linköping, Sweden

Email: emilia.wiechec@liu.se; T: +46-10-10 31534

Key words: 4,4'-diisothiocyanostilbene-2,2'-disulfonic acid (DIDS); voltage-dependent anion channel (VDAC); reactive oxygen species (ROS), ionizing radiation, cell death, DNA strand breaks. 


\begin{abstract}
Background: The voltage-dependent ion channels (VDAC) play an essential role in the cross talk between mitochondria and the rest of the cell. Their implication in cell life and cell death has been studied extensively in recent years. In this work we studied the impact of mitochondrial membrane voltage-dependent anion channels (VDACs) on cell survival and response to X-ionizing radiation (IR) of human lymphoblastoid K562 cells. Methods: The inhibition of VDACs was achieved by 4,4'-diisothiocyanostilbene-2,2'-disulfonic acid (DIDS) inhibitor and in vitro experiments including clonogenity assay, UV-visible spectrophotometry, comet assay and FACS analysis were implemented. Results: Inhibition of VDAC led to augmentation of IR-induced apoptosis and ROS production. Additionally, DIDS affected repair of IR-induced DNA strand breaks and was in line with both induction of apoptosis and caspase activity. The IR-induced NO production was potently reduced by inhibition of VDAC. Conclusion: Our results suggest that VDAC control cellular response to ionizing radiation through modulation of the ROS- and NO-dependent signaling pathways. Inhibition of VDAC with DIDS induced apoptosis in irradiated K562 lymphoblastoid cells points at DIDS, as a promising agent to enhance the effectiveness of radiotherapy.
\end{abstract}




\section{INTRODUCTION}

Exposure of cells to ionizing radiation (IR) induces changes in cellular structures and behavior not only directly, but also by radiolysis of water to form reactive oxygen and nitrogen species (ROS and RNS, respectively). These reactive species modify macromolecules [1] and activate signaling pathways, which lead to inhibition of the cell cycle, induction of apoptosis and DNA repair, as well as intercellular communication resulting in bystander effects in neighboring cells $[1,2]$. Cells start to produce ROS and NO already a few hours after irradiation [3, 4], and ROS generation depends highly on the mitochondrial membrane potential $[3,5,6]$. An increase of mitochondrial membrane permeability and the flux of ions in, and out of the inter-membrane space, are governed by different specific outer and inner mitochondrial membrane channels including voltagedependent chloride channel (VDAC, porins). Furthermore, their role in the regulation of mitochondrial functioning, as well as controlling of cell survival and cell death signals has been widely described in the literature [7-9].

Briefly, VDACs are small $(\sim 30 \mathrm{kDa})$ proteins in the outer membrane of mitochondria of all species studied [10-12]. The flux of ions and small molecules through the mitochondrial membrane is crucial for cellular physiology, and membrane VDACs are one of the players in the control of membrane permeability. In mammals there are 3 isoforms which build channels with slightly different properties [13]. Opening of these channels is regulated by mitochondrial membrane potential, with closure at high values, and their main function is regulating the flow of metabolites such as of ATP and ADP and other respiratory substrates between the cytosol and the mitochondrial intermembrane space $[14,15]$. They are also responsible for the release of superoxide anions $\left(\mathrm{O}_{2}{ }^{-{ }^{-}}\right)$from the mitochondrial intermembrane space to the cytosol [16] and participate in regulating the redox status of the cytoplasm and mitochondria [17, 18]. IR influences ion transporters in cancer cells, including VDACs [19]. 
Furthermore, cancer cells show increased expression of channel proteins in cellular and organelle membranes [20]. The question therefore arises if modulation of the activity of VDAC may participate in the production of ROS and NO in irradiated cells.

4,4'-diisothiocyanostilbene-2,2'-disulfonic acid (DIDS) has been described as a nonspecific VDAC inhibitor [21, 22] influencing various cellular functions including protein and organelle trafficking, as well as DNA repair [23-25]. The effectiveness of DIDS to block mitochondrial anion channels has been well documented in the literature [22, 26, 27].

The aim of the work reported here was to examine the impact of VDAC inhibition on response to IR considering cell cycle progression, apoptosis induction, repair of DNA breaks as well as levels of ROS and NO.

\section{RESULTS AND DISCUSSION}

The effect of DIDS on cell survival and cell cycle progression in irradiated cancer cells

In this work we investigated the role of VDACs in the response of human lymphoblastoid K562 cells to ionizing radiation. We have used DIDS, the unspecific VDAC inhibitor acting on both mitochondrial and plasma membrane channels [21, 22, 28].

At first, to determine whether VDAC inhibition affects radiation-induced toxicity, the clonogenic assay has been applied. The human lymphoblastoid K562 cells underwent combined treatment with DIDS and X-ionizing radiation (IR). Our results showed that DIDS alone does not affect cell survival significantly unlike irradiated cells (Fig 1A). Furthermore, irradiation in the presence of VDAC inhibitor led to a decrease in the surviving fraction of the K562 cells pointing at radiosenitizing role of DIDS (Fig 1A). In addition, no significant effect of DIDS on growth of K562 cells measured by MTT assay was observed (data not shown).

Next, we assessed the impact of IR and DIDS-mediated growth inhibition on cell cycle progression. Cell cycle progression in cultures of control (unirradiated) cells was not affected 
significantly in the presence of DIDS in comparison to irradiated cells (Fig 1B). The ratio of G2/G1 after combined treatment with IR and DIDS at various time points was calculated. We observed an increase in cell cycle arrest, which is illustrated as an increase in G2/G1 ratio over time in the irradiated cells pre-treated with DIDS (Fig 1C). We have demonstrated that DIDS has the radiosensitizing effect on K562 cells and is in concordance with previous research [29, 30]. Recently a large number of radiosensitizers that modulate survival pathways have become available, for example inhibitors of histone deacetylase [31], ataxia telangiectasia mutated protein [32], Raf [33], Hsp90 [34], or PI3K/mTOR [35].

\section{The effect of DIDS on radiation-induced apoptosis}

The sub-G1 population detected by flow cytometry was compared in irradiated cells as well as irradiated cells pre-treated with DIDS. As shown in Figure 2A, IR in combination with DIDS led to significant increase of apoptotic cells in comparison to only irradiated cells. The involvement of VDAC inhibition in the release of cytochrome $\mathrm{c}$ and activation of caspases was also examined. As shown in Figure 2B, the cytochrome $c$ level in the cytosolic fraction of the K562 cells at $48 \mathrm{~h}$ after treatment was significantly incresaed increased in irradiated and DIDS treated cells compared with control cells. Next, we measured the activities of caspases $1,3,8$ and 9 at $48 \mathrm{~h}$ post irradiation to determine whether changes of their activity accompany the increased cell death (Figure 2C). We observed an insignificant increase of caspase- 8 and caspase- 9 activation in the combined treatment of K562 cells with IR and DIDS compared to irradiated cells. It is worth noticing that caspase-3 activity in only DIDS treated cells was significantly higher compared to untreated cells. The increase in caspase-3 activity was not prominent in the irradiated cells upon inhibition of VDAC compared to irradiated cells. Additionally, activity of caspases $1,3,8$ and 9 at $48 \mathrm{~h}$ after irradiation were slightly lower 
compared to unirradiated cells that suggests coexistence of caspase-independent mechanism promoting apoptosis in irradiated cells.

This DIDS-induced apoptosis in irradiated K562 cells is most likely through release of cytochrome $c$ from mitochondria to cytosol and activation of caspase- 8 and 9. Nevertheless, differences in the induction of caspases in irradiated cells and cells co-treated with DIDS were minor. In our study, an apoptotic phenotype illustrated by activation of caspase-1, 3, 8, 9 was comparable in DIDS and IR+DIDS treated cells. Although DIDS treated cells did not exhibit an apparent apoptotic phenotype such as propidium iodide uptake and cytochrome $c$ release from mitochondria, the activation of caspase-3 was observed. A similar phenomenon of DIDS-induced apoptotic phenotype without disruption of plasma membrane integrity has been described previously in hippocampal neuronal cells [36]. However, the above described clonogenic assay showed that proliferation capability of K562 cells after DIDS treatment was not affected significantly when compared to IR+DIDS treated cells. A relatively low activity of caspase-1, 3, 8 and 9 in irradiated cells at $48 \mathrm{~h}$ post-treatment might be a result of masking caspase-dependent cell death by a potentially coexisting and delayed caspase-independent pathway. A similar mechanism has been described in staurosporine-induced apoptosis of acute lymphoid leukemia cells [37].

\section{The effect of DIDS on radiation-induced DNA damage response}

DIDS inhibits RAD51-mediated strand exchange during repair of DNA strand breaks [23], and we therefore examined if it affected repair of radiation-induced DNA strand breaks. DIDS alone did not show significant effect on the frequency of DNA strand breaks. Additionally, our data showed that inhibition of VDAC in irradiated cells inhibits DNA repair unlike only irradiated or DIDS treated cells (Figure 3). 


\section{The effect of DIDS on ROS and NO production in irradiated cells}

First, the effect of VDAC inhibition on ROS production was investigated in K562 cells using DCFH-DA fluorescence. Our results showed that inhibition of VDAC was associated with a significant increase in the IR-induced ROS levels after $24 \mathrm{~h}$ compared to only irradiated cells (Figure 4A). This suggests that increased production of ROS may play an important role in DIDS-induced radio-sensitization. Next, we followed changes of NO levels in K562 cell culture medium up to $24 \mathrm{~h}$ post-irradiation and/or VDAC inhibition using DAF-FM fluorescence [38]. IR led to a strong induction of NO unlike non-irradiated cells. Furthermore, inhibition of VDAC potently decreased IR-induced NO levels (Figure 4B).

DIDS-induced apoptosis in irradiated cells was associated with increased ROS production. It has been shown previously that VDAC inhibition with DIDS leads to loss of mitochondrial membrane potential in irradiated compared to only DIDS treated cells suggesting its VDAC targeting capacity [29]. Additionally, in our earlier report we have shown that increase in ROS production at later time point following IR depends on the mitochondrial complex I activity $[3,4]$. In the present work we showed that DIDS augmented the late production of ROS in irradiated cells, suggesting that mitochondrial VDAC may participate in the regulation of ROS levels directly or indirectly throughout effects on membrane potential. Furthermore, the increase of ROS at $24 \mathrm{~h}$ post-IR was accompanied by increase of DNA damage in irradiated cells. However this IR-induced DNA damage remained in the cells treated with DIDS unlike only irradiated cells. It has been shown that DIDS can suppress homologous recombination-dependent DNA repair by competitive binding to the DNAbinding site in RAD51 and sensitizes cells to IR [23, 30].

In addition to the DNA damage, IR leads to accelerated NO production, which is considered a direct consequence of DNA strand breaks. It has been suggested that radiationinduced NO is associated with radio-resistance of cancer cells [39]. What's more, recent 
findings indicate a novel role of $\mathrm{NO}$ in the regulation of stem-like phenotype in lung cancer cells $[40,41]$. The inhibitory effect of NO on apoptosis via inhibition of caspase activity or decreasing pro-apoptotic level of cGMP has also been proposed [42]. We demonstrated that inhibition of VDAC leads to a decreased production of NO in irradiated lymphoblastoid cells. These findings suggest that DIDS may have a pro-apoptotic effect in irradiated cells and potentially protective effect against cancer progression through modulation of NO production. However, no clear induction of caspase activity has been observed in irradiated cells upon DIDS treatment. Furthermore, NO is a signaling molecule that also affects many mitochondrial functions [43]. High levels of NO acutely inhibit cell respiration by binding to cytochrome c oxidase while chronic, smaller increases stimulate mitochondrial biogenesis [43-45]. Mitochondria contain their specific, $\mathrm{Ca}(2+)$-sensitive mitochondrial NO synthase (mtNOS) whose NO production regulates mitochondrial oxygen consumption and transmembrane potential via a reversible reaction with cytochrome c oxidase (reviewed in [44]). The increased levels of NO in irradiated K562 cells might be a consequence of a larger fraction of cells in the G2 phase stimulating the biogenesis of mitochondria before division.

\section{CONCLUSIONS}

In summary, our results suggest that VDAC control the cell cycle checkpoints and the cellular response to ionizing radiation through modulation of the ROS- and NO-dependent signaling pathways. Inhibition of VDAC with DIDS induced apoptosis in irradiated lymphoblastoid cells points at DIDS as a promising agent to enhance the effectiveness of radiotherapy. 


\section{MATERIALS AND METHODS}

\section{Cell culture, irradiation and DIDS treatment}

Cells of the human myelogenous leukaemia line K562 (ATCC) were grown in RPMI 1640 supplemented with L-glutamine (Sigma-Aldrich), 15\% (vol/vol) fetal bovine serum (Gibco), and $0.04 \%$ gentamycin $(50 \mathrm{mg} / \mathrm{ml})$ in a $5 \% \mathrm{CO}_{2}$ incubator at $37^{\circ} \mathrm{C}$. Exponentially growing cells were irradiated at room temperature with 4 or 12 Gy of $6 \mathrm{MV}$ X-ray photons generated by a therapeutic accelerator (Clinac 600) in fresh culture medium (changed 15 min before irradiation). DIDS (Sigma) was kept in $100 \mathrm{mM}$ stock solutions in DMSO and when required, it was added to the culture medium 15 min prior to irradiation and the cells were incubated with DIDS during and after irradiation for the indicated time.

\section{Analysis of the cell cycle and apoptosis}

DNA content was assayed by flow cytometry (Becton Dickinson, Aria III Sorter) using at least 10,000 cells per sample. Cells were fixed in ice-cold $70 \%$ (vol/vol) ethanol on ice for 30 min, washed with PBS, resuspended in $50 \mu 1 \mathrm{PBS}$, and incubated with $100 \mu \mathrm{g} / \mathrm{ml}$ RNase A (Sigma-Aldrich) at $37{ }^{\circ} \mathrm{C}$ for $15 \mathrm{~min}$, followed by addition of propidium iodide (PI) (Sigma; $100 \mu \mathrm{g} / \mathrm{ml}$ ) at room temperature for $10 \mathrm{~min}$. Apoptotic cells were quantified as the sub-G1 population.

\section{Clonogenity assay}

Cells $\left(10^{5}\right.$ per dish) were seeded onto $6 \mathrm{~cm}$ diameter sterile dishes in culture medium RPMI (Sigma) containing $0.35 \%(\mathrm{wt} / \mathrm{vol})$ low-melting agarose $(\mathrm{ABO}$, Poland) over a $0.7 \%(\mathrm{wt} / \mathrm{vol})$ agarose (ABO, Poland) layer in the presence of irradiation, varying concentartions $(50,500$ 
and $1000 \mu \mathrm{M}$ ) of DIDS or in combination with irradiation. All pre-incubations in suspension were conducted for 30 minutes, than cells were additionally irradiated with X-rays, at doses of 4 and 12 Gy. As controls, untreated K562 cells were used. The culture medium was filled to 5 $\mathrm{ml}$ followed by incubation of cells for 3 weeks. When colony formation was observed (over 50 cells in single colony), cells were stained with $0.005 \%$ (wt/vol) crystal violet (Acros Organics) in PBS containing 4\% formaldehyde and colonies were counted manually from each dish. The plating efficiency index (PE) was calculated for control and treated sets: PE $(\%)=$ counted colonies/seeded cells $\times 100 ;$ and the survival fraction $(\mathrm{SF}): \mathrm{SF}=\mathrm{PE}$ tested/PE control.

\section{Measurements of cytochrome c release}

The Quantikine human cytochrome c (R\&D systems, Cat No. DCTC0) ELISA testing was used for measurements of mitochondrial cytochrome c release in response to DIDS [500 $\mu \mathrm{M}$ ] alone, and DIDS in combination with irradiation [4Gy]. After $24 \mathrm{~h}$ post treatment, cell lysates were prepared and the supernatants were incubated with specific antibodies according to manufacturers instructions. Measurement of optic density was performed for quantification using four parameter logistic (4-PL) curve fit (Excel, Microsoft 2010).

\section{Caspase activity assay}

Caspase activities were determined in cell lysates using colorimetric assay kits (Biomol) with the chromogenic peptidyl substrates YVAD-pNA, DEVD-pNA, IETDpNA and LEHD-pNA for caspases 1,3 , and 8 and 9 respectively. After $2 \mathrm{~h}$ of incubation at $37{ }^{\circ} \mathrm{C}$ absorbance was measured on a NanoDrop spectrophotometer at $405 \mathrm{~nm}$ and standardized using the free colorimetric substrates. Caspase activities were calculated as pmoles of substrate cleaved by1 $\mathrm{mg}$ of protein per $1 \mathrm{~min}$ [46]. The concentration of protein in cell lysates was measured by UV absorption at $280 \mathrm{~nm}$. 


\section{Assays of ROS and NO}

Cellular ROS content was determined using 2',7'-dichlorofluorescein diacetate (DCFH-DA, Sigma). Briefly, cells were collected and labeled with DCFH-DA (10 $\mu \mathrm{M}$ in ethanol) for 30 min at $37{ }^{\circ} \mathrm{C}$ in dark conditions, washed, suspended in PBS and kept for 15 min on ice. To assay NO cells were incubated with 4- amino-5-methylamino-2',7'-difluororescein diacetate (1 $\mu \mathrm{M}$, DAF-FM diacetate, Invitrogen) for $30 \mathrm{~min}$ in dark conditions at $37{ }^{\circ} \mathrm{C}$ and washed with PBS. In both assays the fluorescence intensities of $\sim 10,000$ cells were measured on a flow cytometer (Becton Dickinson, Aria III Sorter) using the $488 \mathrm{~nm}$ laser line, LP mirror 503, and BP filter 530/30.

\section{Assays of DNA strand breaks}

DNA strand breaks were quantified by the alkaline single cell gel electrophoresis (comet) assay according to international recommendations [47]. Briefly $\sim 4 \times 10^{4}$ cells were mixed with 2 volumes of low-melting agarose and immediately transferred onto slides on ice. After the agarose had polymerized, slides were incubated in lysis solution $(2.5 \mathrm{M} \mathrm{NaCl}, 0.1 \mathrm{M}$ EDTA, $10 \mathrm{mM}$ Tris-HCl, 1\% (vol/vol) Triton $\mathrm{X}-100$, $\mathrm{pH} 10$ at $4{ }^{\circ} \mathrm{C}$ ) for $60 \mathrm{~min}$ and in alkaline solution (300 mM NaOH, $1 \mathrm{mM}$ EDTA, pH 13) for $30 \mathrm{~min}$. After electrophoresis in alkaline solution at $0.75 \mathrm{~V} / \mathrm{cm}$ and $300 \mathrm{~mA}$ for $20 \mathrm{~min}$ at $4{ }^{\circ} \mathrm{C}$, slides were washed twice with $0.5 \mathrm{M}$ Tris, $\mathrm{pH} 7.4$, fixed in $96 \%$ (vol/vol) ethanol and stained with ethidium bromide. The tail moment (percentage of total DNA in tail $\mathrm{x}$ distance between centers of head and tail) was calculated for $\sim 100$ cells per slide using comet scoring software (CometScore, TriTek Corp.) and expressed as the mean value.

\section{Statistical analyses}

At least three replicates of all experiments were performed and results are expressed as mean \pm SD. Differences were regarded as statistically significant when P calculated by the twosided Student $\mathrm{t}$ test was $<0.05$. 


\section{CONFLICT OF INTEREST}

The authors declare no potential conflicts of interest.

\section{ACKNOWLEDGEMENTS}

This work was supported by the National Science Center [grant number DEC2012/07/B/NZ1/00008 and NCN 2015/19/B/ST7/02984]. Biological experiments were performed at the Biotechnology, Bioengineering and Bioinformatics Centre of the Silesian BIO-FARMA, created within the Innovative Economy Operational Programme (POIG) 02.01.00-00-166/08 and expanded in the POIG.02.03.01-00-040/13 projects. Prof. Ronald Hancock (Laval University, Canada) is acknowledged for critically reading the manuscript.

\section{REFERENCES}

[1] LeCaër, S., Water radiolysis: influence of oxide surfaces on $\mathrm{H} 2$ production under ionizing radiation. Water, 2011, 3, 235-253.

[2] Rzeszowska-Wolny, J.; Przybyszewski, W.M.; Widel, M., lonizing radiation-induced bystander effects, potential targets for modulation of radiotherapy. Eur J Pharmacol, 2009, 625, (1-3), 156-164.

[3] Saenko, Y.; Cieslar-Pobuda, A.; Skonieczna, M.; Rzeszowska-Wolny, J., Changes of reactive oxygen and nitrogen species and mitochondrial functioning in human K562 and HL60 cells exposed to ionizing radiation. Radiat Res, 2013, 180, (4), 360-366.

[4] Cieslar-Pobuda, A.; Saenko, Y.; Rzeszowska-Wolny, J., PARP-1 inhibition induces a late increase in the level of reactive oxygen species in cells after ionizing radiation. Mutat Res, 2012, 732, (1-2), 9-15.

[5] Kowaltowski, A.J.; de Souza-Pinto, N.C.; Castilho, R.F.; Vercesi, A.E., Mitochondria and reactive oxygen species. Free radical biology \& medicine, 2009, 47, (4), 333-343.

[6] Starkov, A.A.; Fiskum, G., Regulation of brain mitochondrial $\mathrm{H} 2 \mathrm{O} 2$ production by membrane potential and NAD(P)H redox state. J Neurochem, 2003, 86, (5), 1101-1107.

[7] Leanza, L.; Biasutto, L.; Manago, A.; Gulbins, E.; Zoratti, M.; Szabo, I., Intracellular ion channels and cancer. Frontiers in physiology, 2013, 4, 227.

[8] Bose, T.; Cieslar-Pobuda, A.; Wiechec, E., Role of ion channels in regulating Ca homeostasis during the interplay between immune and cancer cells. Cell death \& disease, 2015, 6, e1648.

[9] Shoshan-Barmatz, V.; De Pinto, V.; Zweckstetter, M.; Raviv, Z.; Keinan, N.; Arbel, N., VDAC, a multi-functional mitochondrial protein regulating cell life and death. Mol Aspects Med, 2010, 31, (3), 227-285.

[10] Colombini, M., A candidate for the permeability pathway of the outer mitochondrial membrane. Nature, 1979, 279, (5714), 643-645.

[11] Kleene, R.; Pfanner, N.; Pfaller, R.; Link, T.A.; Sebald, W.; Neupert, W.; Tropschug, M., Mitochondrial porin of Neurospora crassa: cDNA cloning, in vitro expression and import into mitochondria. The EMBO journal, 1987, 6, (9), 2627-2633. 
[12] Colombini, M., VDAC: the channel at the interface between mitochondria and the cytosol. Mol Cell Biochem, 2004, 256-257, (1-2), 107-115.

[13] Messina, A.; Reina, S.; Guarino, F.; De Pinto, V., VDAC isoforms in mammals. Biochim Biophys Acta, 2012, 1818, (6), 1466-1476.

[14] Lemasters, J.J.; Holmuhamedov, E., Voltage-dependent anion channel (VDAC) as mitochondrial governator--thinking outside the box. Biochim Biophys Acta, 2006, 1762, (2), 181-190.

[15] Lemasters, J.J.; Holmuhamedov, E.L.; Czerny, C.; Zhong, Z.; Maldonado, E.N., Regulation of mitochondrial function by voltage dependent anion channels in ethanol metabolism and the Warburg effect. Biochim Biophys Acta, 2012, 1818, (6), 1536-1544.

[16] Han, D.; Antunes, F.; Canali, R.; Rettori, D.; Cadenas, E., Voltage-dependent anion channels control the release of the superoxide anion from mitochondria to cytosol. $J$ Biol Chem, 2003, 278, (8), 5557-5563.

[17] Kushnareva, Y.E.; Sokolove, P.M., Prooxidants open both the mitochondrial permeability transition pore and a low-conductance channel in the inner mitochondrial membrane. Arch Biochem Biophys, 2000, 376, (2), 377-388.

[18] Galganska, H.; Budzinska, M.; Wojtkowska, M.; Kmita, H., Redox regulation of protein expression in Saccharomyces cerevisiae mitochondria: possible role of VDAC. Arch Biochem Biophys, 2008, 479, (1), 39-45.

[19] Huber, S.M.; Butz, L.; Stegen, B.; Klumpp, D.; Braun, N.; Ruth, P.; Eckert, F., lonizing radiation, ion transports, and radioresistance of cancer cells. Frontiers in physiology, 2013, 4, 212.

[20] Monteith, G.R.; Davis, F.M.; Roberts-Thomson, S.J., Calcium channels and pumps in cancer: changes and consequences. J Biol Chem, 2012, 287, (38), 31666-31673.

[21] Beavis, A.D.; Davatol-Hag, H., The mitochondrial inner membrane anion channel is inhibited by DIDS. Journal of bioenergetics and biomembranes, 1996, 28, (2), 207-214.

[22] Tomaskova, Z.; Gaburjakova, J.; Brezova, A.; Gaburjakova, M., Inhibition of anion channels derived from mitochondrial membranes of the rat heart by stilbene disulfonate--DIDS. $J$ Bioenerg Biomembr, 2007, 39, (4), 301-311.

[23] Ishida, T.; Takizawa, Y.; Kainuma, T.; Inoue, J.; Mikawa, T.; Shibata, T.; Suzuki, H.; Tashiro, S.; Kurumizaka, H., DIDS, a chemical compound that inhibits RAD51-mediated homologous pairing and strand exchange. Nucleic Acids Res, 2009, 37, (10), 3367-3376.

[24] Jungnickel, B.; Rapoport, T.A., DIDS (4,4'-diisothiocyanatostilbene-2,2'-disulfonic acid) inhibits an early step of protein translocation across the mammalian ER membrane. FEBS Lett, 1993, 329, (3), 268-272.

[25] Liu, C.J.; Hwang, J.M.; Wu, T.T.; Hsieh, Y.H.; Wu, C.C.; Hsieh, Y.S.; Tsai, C.H.; Wu, H.C.; Huang, C.Y.; Liu, J.Y., Anion exchanger inhibitor DIDS induces human poorly-differentiated malignant hepatocellular carcinoma HA22T cell apoptosis. Mol Cell Biochem, 2008, 308, (1-2), 117-125.

[26] Beavis, A.D.; Davatol-Hag, H., The mitochondrial inner membrane anion channel is inhibited by DIDS. J Bioenerg Biomembr, 1996, 28, (2), 207-214.

[27] Koszela-Piotrowska, I.; Choma, K.; Bednarczyk, P.; Dolowy, K.; Szewczyk, A.; Kunz, W.S.; Malekova, L.; Kominkova, V.; Ondrias, K., Stilbene derivatives inhibit the activity of the inner mitochondrial membrane chloride channels. Cell Mol Biol Lett, 2007, 12, (4), 493-508.

[28] Pamenter, M.E.; Ali, S.S.; Tang, Q.; Finley, J.C.; Gu, X.Q.; Dugan, L.L.; Haddad, G.G., An in vitro ischemic penumbral mimic perfusate increases NADPH oxidase-mediated superoxide production in cultured hippocampal neurons. Brain research, 2012, 1452, 165-172.

[29] Saenko, Y.V.; Mastilenko, A.V.; Glushchenko, E.S.; Antonova, A.V.; Svekolkin, V.P., Inhibition of Mitochondrial Voltage-Dependent Anion Channels Increases Radiosensitivity of K562 Leukemic Cells. Bull Exp Biol Med, 2016, 161, (1), 104-107.

[30] Lamont, K.R.; Hasham, M.G.; Donghia, N.M.; Branca, J.; Chavaree, M.; Chase, B.; Breggia, A.; Hedlund, J.; Emery, I.; Cavallo, F.; Jasin, M.; Ruter, J.; Mills, K.D., Attenuating homologous recombination stimulates an AID-induced antileukemic effect. J Exp Med, 2013, 210, (5), 1021-1033. 
[31] Dong, Q.H.; Sharma, S.; Liu, H.; Chen, L.; Gu, B.X.; Sun, X.N.; Wang, G.Y., HDAC inhibitors reverse acquired radio resistance of KYSE-150R esophageal carcinoma cells by modulating Bmi-1 expression. Toxicol Lett, 2014, 224, (1), 121-129.

[32] Vecchio, D.; Daga, A.; Carra, E.; Marubbi, D.; Baio, G.; Neumaier, C.E.; Vagge, S.; Corvo, R.; Pia Brisigotti, M.; Louis Ravetti, J.; Zunino, A.; Poggi, A.; Mascelli, S.; Raso, A.; Frosina, G., Predictability, efficacy and safety of radiosensitization of glioblastoma-initiating cells by the ATM inhibitor KU60019. Int J Cancer, 2013.

[33] Laban, S.; Steinmeister, L.; Gleissner, L.; Grob, T.J.; Grenman, R.; Petersen, C.; Gal, A.; Knecht, R.; Dikomey, E.; Kriegs, M., Sorafenib sensitizes head and neck squamous cell carcinoma cells to ionizing radiation. Radiotherapy and oncology : journal of the European Society for Therapeutic Radiology and Oncology, 2013, 109, (2), 286-292.

[34] Gandhi, N.; Wild, A.T.; Chettiar, S.T.; Aziz, K.; Kato, Y.; Gajula, R.P.; Williams, R.D.; Cades, J.A.; Annadanam, A.; Song, D.; Zhang, Y.; Hales, R.K.; Herman, J.M.; Armour, E.; DeWeese, T.L.; Schaeffer, E.M.; Tran, P.T., Novel Hsp90 inhibitor NVP-AUY922 radiosensitizes prostate cancer cells. Cancer Biol Ther, 2013, 14, (4), 347-356.

[35] Kuger, S.; Graus, D.; Brendtke, R.; Gunther, N.; Katzer, A.; Lutyj, P.; Polat, B.; Chatterjee, M.; Sukhorukov, V.L.; Flentje, M.; Djuzenova, C.S., Radiosensitization of Glioblastoma Cell Lines by the Dual PI3K and mTOR Inhibitor NVP-BEZ235 Depends on Drug-Irradiation Schedule. Translational oncology, 2013, 6, (2), 169-179.

[36] Pamenter, M.E.; Perkins, G.A.; Gu, X.Q.; Ellisman, M.H.; Haddad, G.G., DIDS (4,4diisothiocyanatostilbenedisulphonic acid) induces apoptotic cell death in a hippocampal neuronal cell line and is not neuroprotective against ischemic stress. Plos One, 2013, 8, (4), e60804.

[37] Belmokhtar, C.A.; Hillion, J.; Segal-Bendirdjian, E., Staurosporine induces apoptosis through both caspase-dependent and caspase-independent mechanisms. Oncogene, 2001, 20, (26), 33543362.

[38] Kojima, H.; Nakatsubo, N.; Kikuchi, K.; Kawahara, S.; Kirino, Y.; Nagoshi, H.; Hirata, Y.; Nagano, T., Detection and imaging of nitric oxide with novel fluorescent indicators: diaminofluoresceins. Anal Chem, 1998, 70, (13), 2446-2453.

[39] Nagane, M.; Yasui, H.; Yamamori, T.; Zhao, S.; Kuge, Y.; Tamaki, N.; Kameya, H.; Nakamura, H.; Fujii, H.; Inanami, O., Radiation-induced nitric oxide mitigates tumor hypoxia and radioresistance in a murine SCCVII tumor model. Biochem Biophys Res Commun, 2013, 437, (3), 420-425.

[40] Yongsanguanchai, N.; Pongrakhananon, V.; Mutirangura, A.; Rojanasakul, Y.; Chanvorachote, P., Nitric oxide induces cancer stem cell-like phenotypes in human lung cancer cells. Am J Physiol Cell Physiol, 2015, 308, (2), C89-100.

[41] Kim, R.K.; Suh, Y.; Cui, Y.H.; Hwang, E.; Lim, E.J.; Yoo, K.C.; Lee, G.H.; Yi, J.M.; Kang, S.G.; Lee, S.J., Fractionated radiation-induced nitric oxide promotes expansion of glioma stem-like cells. Cancer Sci, 2013, 104, (9), 1172-1177.

[42] Kim, Y.M.; Bombeck, C.A.; Billiar, T.R., Nitric oxide as a bifunctional regulator of apoptosis. Circ Res, 1999, 84, (3), 253-256.

[43] Nisoli, E.; Clementi, E.; Paolucci, C.; Cozzi, V.; Tonello, C.; Sciorati, C.; Bracale, R.; Valerio, A.; Francolini, M.; Moncada, S.; Carruba, M.O., Mitochondrial biogenesis in mammals: the role of endogenous nitric oxide. Science, 2003, 299, (5608), 896-899.

[44] Ghafourifar, P.; Cadenas, E., Mitochondrial nitric oxide synthase. Trends in pharmacological sciences, 2005, 26, (4), 190-195.

[45] Nisoli, E.; Carruba, M.O., Nitric oxide and mitochondrial biogenesis. J Cell Sci, 2006, 119, (Pt 14), 2855-2862.

[46] Tatsuta, T.; Shiraishi, A.; Mountz, J.D., The prodomain of caspase-1 enhances Fas-mediated apoptosis through facilitation of caspase-8 activation. J Biol Chem, 2000, 275, (19), 14248-14254.

[47] Tice, R.R.; Agurell, E.; Anderson, D.; Burlinson, B.; Hartmann, A.; Kobayashi, H.; Miyamae, Y.; Rojas, E.; Ryu, J.C.; Sasaki, Y.F., Single cell gel/comet assay: guidelines for in vitro and in vivo genetic toxicology testing. Environmental and molecular mutagenesis, 2000, 35, (3), 206-221. 
Figure legends:

\section{Figure (1)}

The effect of DIDS on cell survival and cell cycle progression in irradiated K562 cells. Clonogenic assay for K562 cells irradiated (4Gy and 12Gy) in the presence (50 $\mu \mathrm{M}, 500 \mu \mathrm{M}$, $1000 \mu \mathrm{M}$ ) or absence of DIDS is shown (A). Flow cytometry analysis of cell cycle progression in K562 cells grown in the presence or absence of DIDS (500 $\mu \mathrm{M})$ and irradiated (B). Cell cycle analysis expressed as a ratio of the numbers of cells in the G2 phase to those in the G1 phase (C). Results are presented as mean values \pm S.D. of $n=3$ experiments. ${ }^{*}$ denotes statistically significant values between IR and IR+DIDS cells $(\mathrm{p}<0.05)$.

\section{Figure (2)}

The effect of DIDS on radiation-induced apoptosis. Frequency of apoptotic cells in the fraction of sub-G1 K562 cells at $48 \mathrm{~h}$ post-IR (4 Gy) in the presence or absence of $500 \mu \mathrm{M}$ DIDS (A). Cytochrome c release present in the cytosol of K562 cells at $24 \mathrm{~h}$ post-treatment with DIDS $(500 \mu \mathrm{M})$ and DIDS in combination with irradiation [4Gy] analyzed with ELISA (B). Activity of caspases (1, 3, 8 and 9) at 48h post-IR (4 Gy) in the presence or absence of $500 \mu \mathrm{M}$ DIDS was determined by colorimetric assay (C). Results are presented as mean values \pm S.D. of $n=3$ experiments. *denotes statistically significant values in comparison to control (untreated) cells $(\mathrm{p}<0.05)$; \# denotes statistically significant values between IR and IR+DIDS cells $(\mathrm{p}<0.05)$.

\section{Figure (3)}

The effect of DIDS on DNA repair in irradiated cells. Recovery of DNA damage in irradiated K562 cells grown in the presence or absence of DIDS (500 $\mu \mathrm{M})$ was assessed by comet assay, in which DNA repair is equivalent to a decrease in comet size at indicated time point. Results are presented as mean values \pm S.D. of $n=3$ experiments. ${ }^{*}$ denotes statistically 
significant values in comparison to control (untreated) cells $(\mathrm{p}<0.05)$; \# denotes statistically significant values between IR and IR+DIDS cells $(p<0.05)$. Error bars are omitted due to obscuring the clarity of the graph. Each point on the graph represents a mean of over $>100$ cells.

\section{Figure (4)}

The effect of DIDS on ROS and NO production in irradiated cells. Levels of intracellular ROS (A) and NO (B) in K562 cells measured at different time post-IR (4 Gy) with or without DIDS $(500 \mu \mathrm{M})$ treatment. The relative levels of ROS in K562 cells are presented as fold change compared to unirradiated control cells. Results are presented as mean values \pm S.D. of $\mathrm{n}=3$ experiments. * denotes statistically significant values in comparison to control (untreated) cells $(p<0.05)$; \# denotes statistically significant values between IR and IR+DIDS cells $(\mathrm{p}<0.05)$ 
A
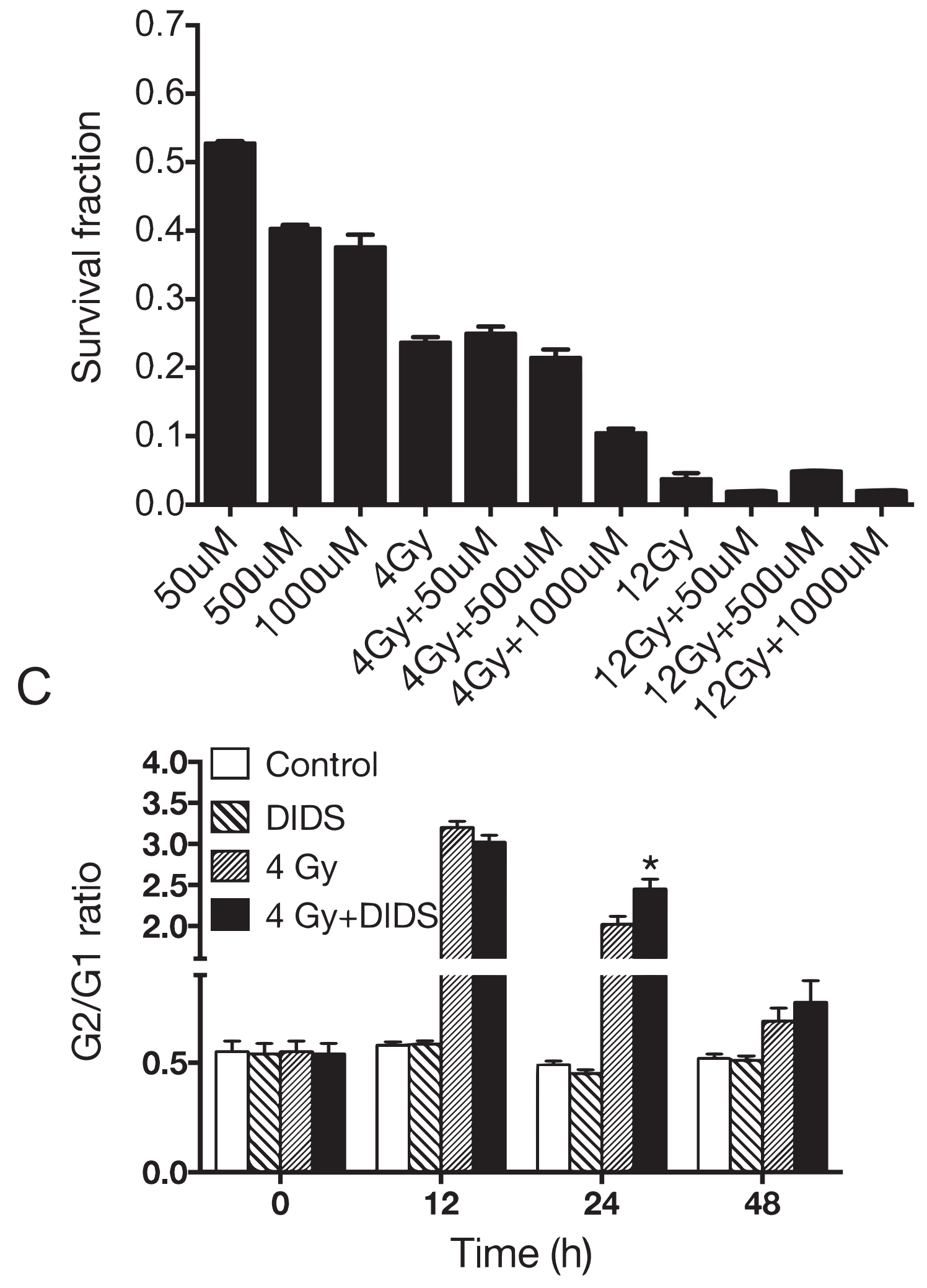
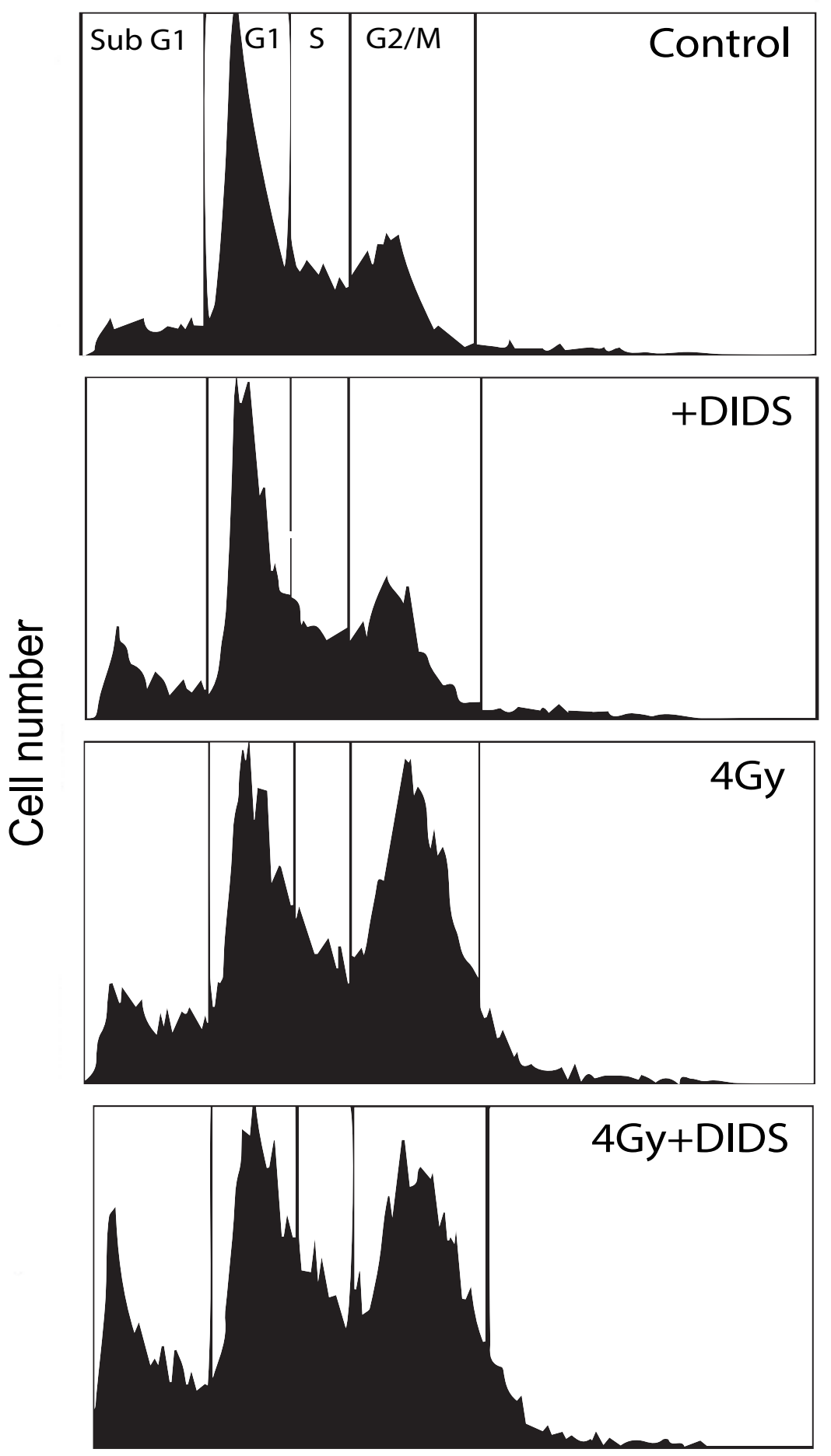

DNA content 
A

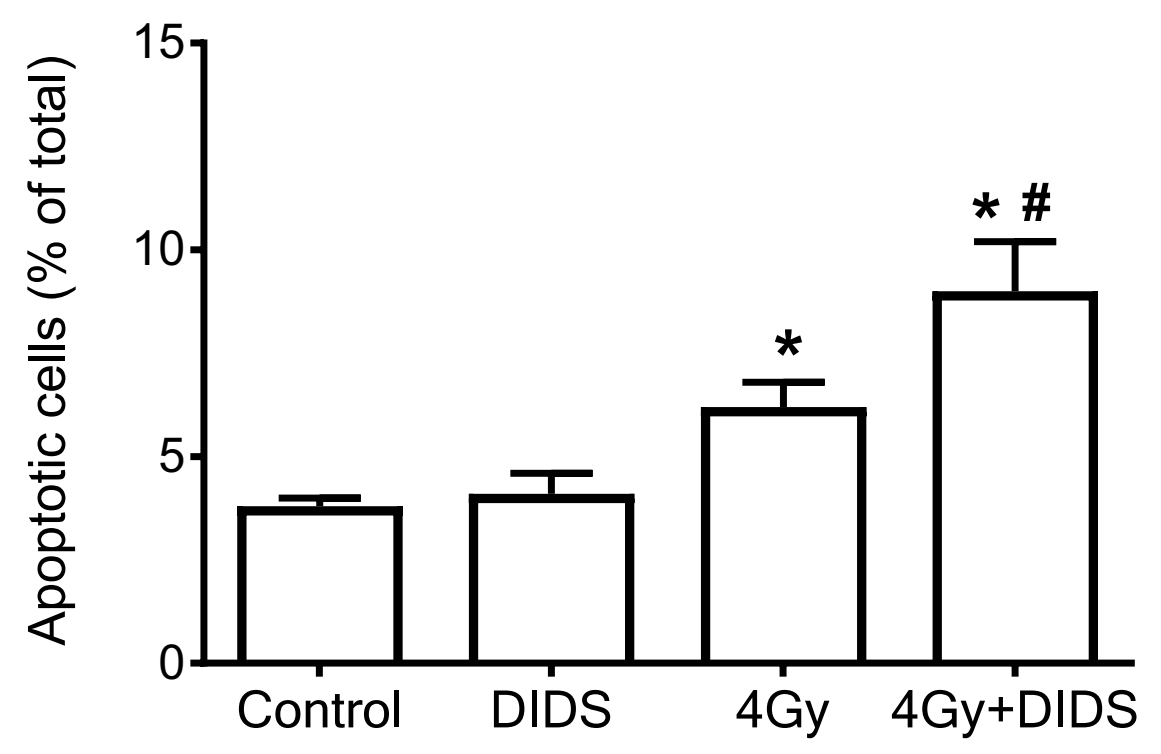

C

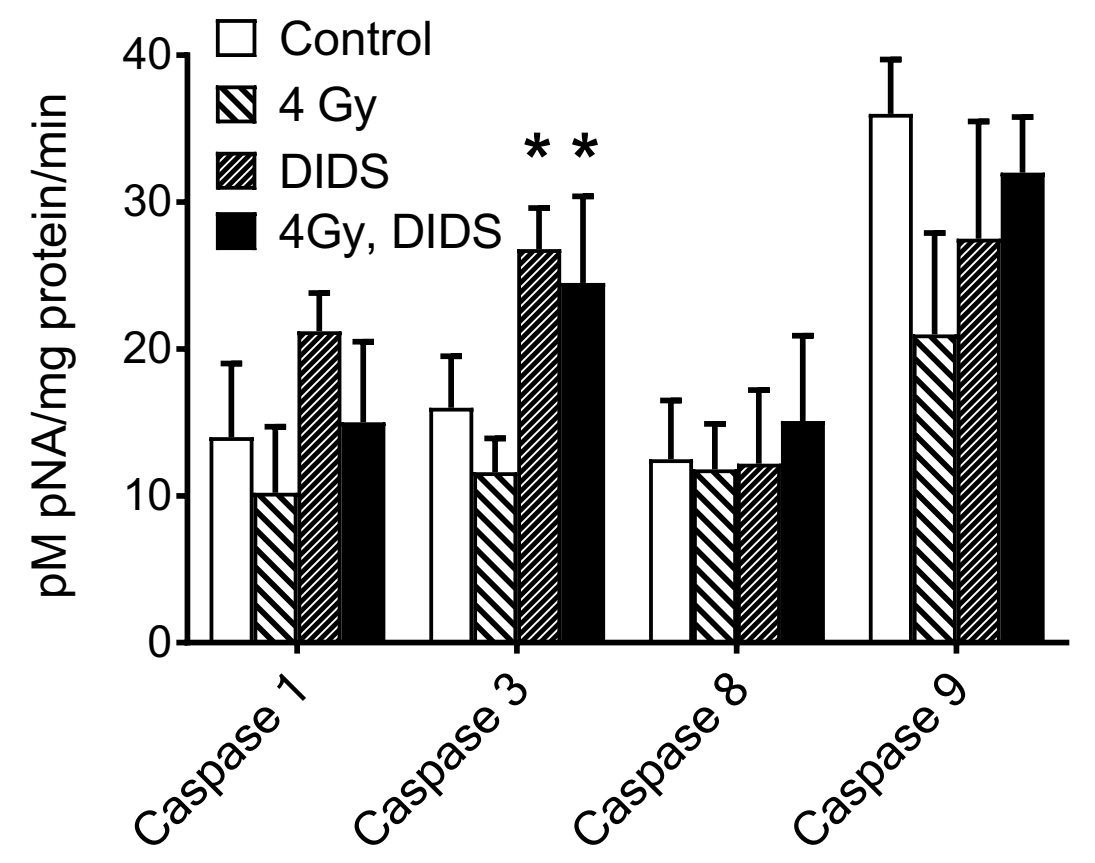

B

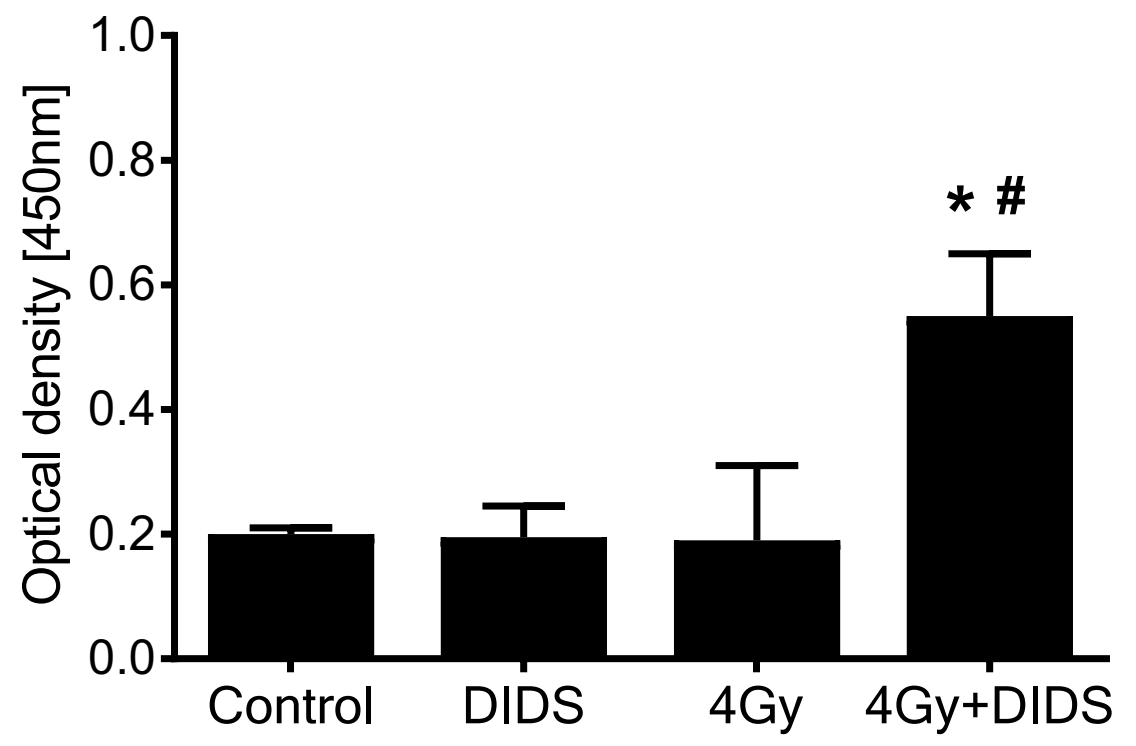




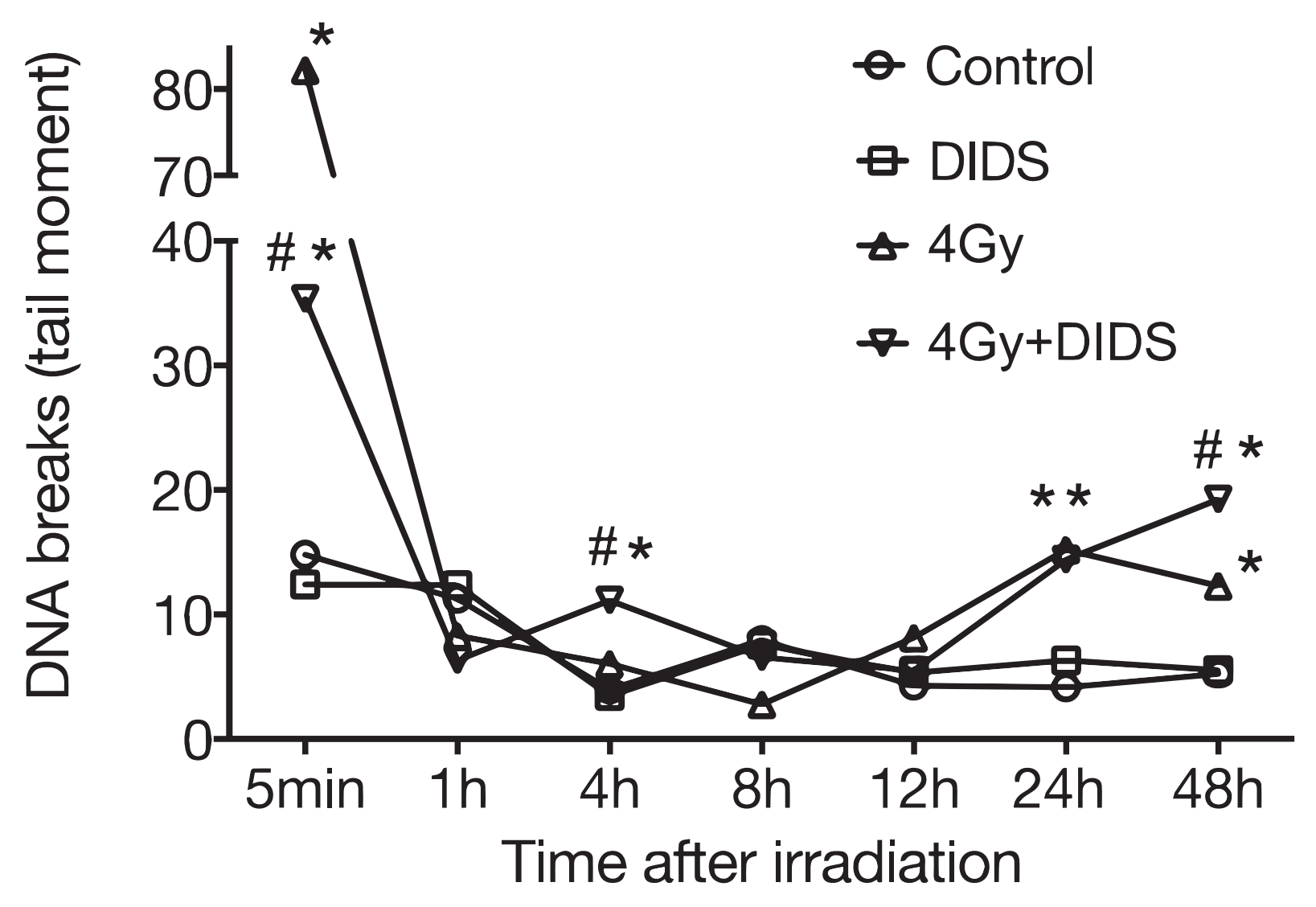



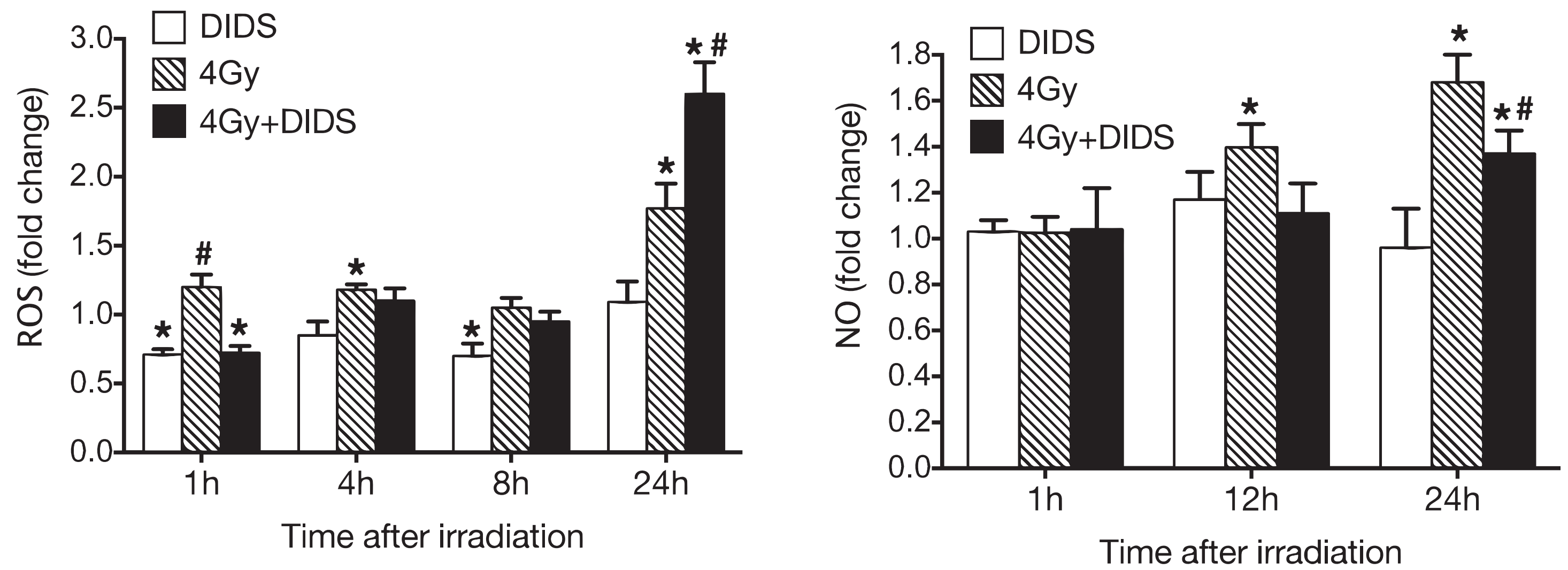